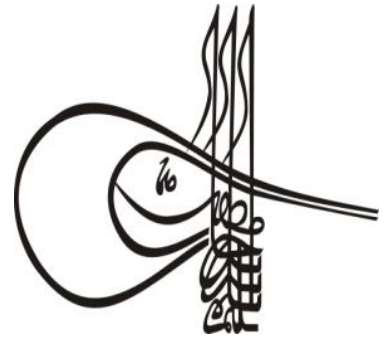

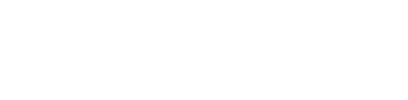

Received/Geliș: 09.07.2019

Go Report Dates/Rapor Tarihleri: Referee 1 (28.07.2019)-Referee 2 (25.07.2019)

Research Article / Araştırma Makalesi

Article Info/Makale Bilgisi

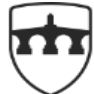

INTERNATIONAL BALKAN UNIVERSITY

EXCELLENCE FOR THE FUTURE IBU.EDU.MK

This article was checked by iThenticate.

\title{
1967-1970 YILLARINDAKİ DİLDE SADELEŞME VE AKADEMİ TARTIŞMALARININ TÜRK KÜLTÜRÜ DERGİSINE YANSIMALARI
}

\author{
Ümit YEGEN* - Mehmet ÖZDEMIRR ${ }^{* *}$
}

\begin{abstract}
öz
Medeniyet değiştirme süreci İslam medeniyeti ile Batı medeniyeti arasında kalan Türk toplumunun dilini de derin ve kalıcı bir biçimde etkilemiştir. Batılllaşma sürecinde, dile giren kelimelerden ziyade, genellikle Arapça ve Farsçadan alınan kelimelerin sadeleştirme/özleştirme çerçevesinde değerlendirilmesi özleştirme kisvesi altında bir tasfiye sürecini de beraberinde getirmiştir. 19671970 yılları arasında "Öz Türkçe" adı altında özleștirme meselesini "devrim" çerçevesinde değerlendirenler ile "yaşayan Türkçe"yi savunarak "millî dil"e hizmet ettiklerini söyleyenlerin Türkçe adına yaptıklarını iddia ettikleri çalışmalar değerlendirilmeye çalışılmıştır.

"Öz Türkçe" yanlıları hiçbir kural tanımayarak kelime üretirken, Türkçeyi yabancı dillerin etkisinden kurtardıklarını ifade etmişlerdir. $\mathrm{Bu}$ durumun yanlışlığı: Osmanlı Türkçesinde kullanılmakta olan Arapça ve Farsça kelimeler yerine Fransızca, Latince veya İngilizce karşılıklarını yerleştirme çabaları görülebilmektedir. Türkçeyi yabancı bir dilin etkisinden kurtarmaya çalışı başka bir yabancı dilin boyunduruğu altına sokmanın "özleştirme" olarak sunulması da ayrıca dikkat çekicidir. Söz konusu karşıtlıkta olduğu gibi birçok dikkat çekici ifade betimlenip çeşitli başlıklar altında sunulmuştur.

Araştırmada "Akademi" konusu da irdelenmiştir. Dil Akademisi kurulması düşüncesi Türk Dil Kurumunun, siyasi değişmelerden ve iktidarlardan etkilenip çok fazla ideolojik davranmasindan kaynaklanmış bir ihtiyaç olarak ortaya çıktığı belirlenmiştir. Dilde sadeleşme çabalarının, siyasilerden çok bu konudaki uzman
\end{abstract}

Sakarya Üniversitesi Eğitim Bilimleri Enstitüsü Doktora Öğrencisi, E-posta: umit_yegen@ @otmail.com

Dr. Öğr. Üyesi, Sakarya Üniversitesi, E-posta: mehmetoz@sakarya.edu.tr 
akademisyen, edebiyatçı ve dilciler tarafından sürdürülmesini savunanlar ve onların Akademi kurulması için çabalarını nasıl sürdürdükleri incelenmiş ve değerlendirilmiştir.

Siyasi-ideolojik eylem ve söylemlerden ayrı tutulması gereken dil meselesi, sadece dil alanında uzman kişilerin ilmî nazarında değerlendirilmelidir. Hedef; aşırıya kaçmadan, dilin tabii seyrini etkilemeden, kültürümüze zarar vermeden değișiklik- yenilik yapmak ve Türkçeyi geliştirerek sonraki nesillere ifade gücü yüksek zengin bir dil birakmak, olmalıdir.

Anahtar Kelimeler: Sadeleşme, Dil Akademisi, Türk Kültürü Dergisi, Öz Türkçe, Yaşayan Türkçe

\title{
REFLECTIONS OF LANGUAGE SIMPLIFICATION AND ACADEMY DISCUSSIONS BETWEEN 1967-1970 TO THE JOURNAL OF TURKISH CULTURA
}

\begin{abstract}
The process of civilization change affected the Turkish society's language profoundly and permanently, since it remains in between Islamic civilization and Western civilization. During the westernization process, rather than the words that are introduced to our language, evaluation of Arabic and Farsi words within the scope of simplification/nativisation, brought an eliminiation process under the guise of nativisation. Between 1967 and 1970, works of the people evaluating the nativisation under the name of "Pure Turkish" within the frame of "revolution" and the people claiming that they are serving to the "national language" by defending the "living Turkish" are evaluated.

"Pure Turkish" advocates claimed that they saved Turkish from the influence of foreign languages while producing words without recognizing any rules. The mistake in this situation: Attempts to replace Arabic and Persian words used in Ottoman Turkish with French, Latin or English, can be seen. It is also noteworthy that trying to save Turkish from the influence of a foreign language and putting it under the yoke of another foreign language was presented as "purification." As in this contrast, many remarkable expressions have been described and presented under various titles.

In the research, the subject of "Academy" was also examined. The idea of thought in the Language Academy was explained before the Turkish Language Institution was influenced by political changes and power, and originated from too much ideological behavior. The people who advocates the language simplification efforts by expert academics, writers and linguists rather than politicians and how they continue their efforts for the establishment of an academy are examined and evaluated.
\end{abstract}

The question of language, which must be kept apart from political-ideological actions and discourses, should be considered only in the scientific view of experts in the field of language. Target; without moderation, without affecting the natural course of the language, 
without damaging our culture, to make changes and innovations, and It must be to leave a rich language with high expression power for next generation by developing Turkısh language.

\section{STRUCTURED ABSTRACT}

Turkish language, whose interaction with Arabic and Persian became more often with the acceptance of Islam, and with Western languages with the Tanzimat period, has influenced the languages in question with exchange of various words or rules; or rather has been influenced by them. The simplification can be expressed as leaving the foreign words that are not understood by the public and using words living in our language and understood by everyone. These foreign words in Turkish and the issue of simplification in the language did not come to the fore until the Tanzimat period, but in later periods the idea of simplification continued to spread, turning into an issue studied and debated in detail. However, during the process of simplification, it was not possible to find a middle way because of the mistakes of "exaggeration and understatement" as the elders say. In fact, the principles and the cautious approach initiated on "simplification" by the young writers could have been more useful and correct in terms of the Turkish language if they had been maintained in the later periods.

Between 1967-1970, the journal, "Türk Kültürü Dergisi," one of the magazines in which simplification discussions were intensified, has been analyzed by document analysis. The articles and responses to those articles of those who support "Pure Turkish" and "Alive Turkish" are considered to be significant in terms of reflecting the political atmosphere of the period. In terms of the conditions of the period, the movement to change the language, especially at the TRT, was clearly demonstrated by the articles in the journal. While the advocates of the "Living Turkish" stated that using the TRT in such an elimination process, which was allegedly called a revolution, would be a fundamental annihilation and using a state institution in such a matter as a "castle" was wrong, for those who advocated the "Pure Turkish" claimed, on the contrary, that the TRT was used for "saving the language from the influence of foreign languages." The most striking element of the TRT was the fact that those who worked in the institution were generally chosen from "Pure Turkish" supporters.

The mentality, which tries to reduce the Ottoman Turkish to Arabic, underdevelopment or Islamism, aims to raise a younger generation without being aware of their ancestors. Trying to eradicate the elements that make the soil we live on a "homeland" from the minds of the younger generations means to erase the Turkish language, which is a bridge with a history of at least nine centuries. It is clear that a generation that is unaware of many values from the stories of Dede Korkut to the wisdom of Ahmet Yesevi, from Kerem and Asl to the poems of Yahya Kemal and many others, will grow up far from the consciousness of national culture and the richness of the Turkish language.

The number of those who expressed a positive opinion in the establishment of the Academy in the said period was quite high. The existence of an institution that can control our language, keep up with the 
changes, and examine the language issue in detail within the framework of our national cult, is undoubtedly necessary. With the presence of a language academy, it seems possible to keep up with the changes brought about by the political, economic and social conditions of the period, in other words, to save our language, which is the bearer of our culture and an essential part of our identity, from any sorts of unnecessary interventions. Misdirection of the language by incompetent people, which also represents the essence of a nation, has brought many discussions along. The existence of an authoritarian institution that will have the last word on these discussions is also necessary for cultural transfer terms.

It can be said that the mentality that opposed the language academy and tried to undermine the Turkish culture with fabricated vocabulary, and that performed this by means of state institutions such as the TRT and the TDK was at the same point as a generation that is trying to exist with limited vocabulary today and an insufficient expressional capability. As a matter of fact, it can be said that the said insufficiency is one of the results of what tried to be done in that period.

National man of letters such as Ömer Seyfettin and Ziya Gökalp expressed the discomfort of the fact that Ottoman written language contains unnecessary foreign words and grammatical forms. The evergrowing gap between the artificial Ottoman Turkish used by the intellectuals and the language spoken by the public caused the issue of simplification to be evaluated in this way by other intellectuals. The language in its own media has changed without any political or social intervention. As it is seen, the issue is not "purification". This issue was resolved years ago. How can the revival of this issue in the 1960s be explained other than the desire to destroy the Turkish culture and make Turkish an inadequate language? Those who settled in state institutions as a result of the political conditions of the period and who did not see Ottoman Turkish as a language of civilization actually damaged our language and culture and their development. These damages and the following problems, as well as the social polarization, were expressed through various articles in the Turkish Culture magazine in the 1960s, and this reproach was compiled and evaluated with today's conditions.

Keywords: Simplification, Language Academy, Journal of Turkish Culture Researches, Pure Turkish, Living Turkish

\section{Giriş}

"Dil nedir?" sorusu, bilim insanı, araştırmacı ve düşünürlerin eskiden bu yana cevap aradıkları ve açıklamaya çalıştıkları bir sorudur. En genel anlamıyla dil, insanların duygu, düşünce ve gözlemlerini işaret veya kelimelerle paylaştıkları bir sistemdir. Bu sistem ses, kelime, cümle, işaret gibi çeşitli ögelerle dile özgü kural, yöntem, beceri ve tekniklerden oluşmaktadır (Güneş 2013: 21). Bu tanıma bakıldığında dilin, birçok yönünün olduğu söylenebilir.

Dil bir anda düşünemeyeceğimiz kadar çok yönlü, değişik açıdan bakılınca da çeşitli nitelikleri özellikleri ortaya çıkabilen büyülü bir varlıktır (Aksan, 2003). Türkçe Sözlükte dil şöyle tanımlanmaktadır: "İnsanların düşündüklerini ve duyduklarını bildirmek için kelimelerle veya işaretlerle yaptıkları anlaşma, lisan” (Türk Dil Kurumu [TDK], 2010: 526). Ergin'in yapmış olduğu en 
kapsamlı tanıma göre (2002: 3) "Dil, insanlar arasında anlaşmayı sağlayan tabii bir vasıta, kendisine mahsus kanunları olan ve ancak bu kanunlar çerçevesinde gelişen canlı bir varlık, temeli bilinmeyen zamanlarda atılmış bir gizli anlaşmalar sistemi, seslerden örülmüş içtimaî bir müessesedir." Diğer bir tanımda ise dil: "Sözcüklerin mantıkî bir diziliş içinde bir araya gelmesinden oluşmuş iletişim vasıtasıdır" (Aktaş- Gündüz, 2011: 8). Bütün bu tanımlamalardan anlaşılacağı üzere dil, insan için çok önemli olmakla beraber dünyayı ve yaşadığımız hayatı anlamlandırma sürecinde de olmazsa olmaz bir öneme sahiptir.

İnsanların birlikte yaşama zorunluluğu, onları aralarında çeşitli yasalar koymaya zorunlu hâle getirir. Dili ile toplum arasında sıkı bir bağ vardır ve tarihi süreçte, değişimlerden her ikisi de etkilenmiş ve birbirini etkilemişlerdir. Dilin toplumsal bir olgu olduğunu söyleyen Wilhelm von Humboldt'a göre diller özgür olarak doğmazlar, ilişkin oldukları insan topluluklarına bağlı olarak belli sınırlar içinde ilerler, milletlerle birlikte gelişir, onların manevî özelliklerinden oluşur. Bu bakımdan insan topluluklarında hadiseler doğru olarak anlaşılmak isteniyorsa, bir ulusun karakterini en açık şekilde ortaya koyan, gelişmeleri en iyi gösteren, dil üzerinde durulmalıdır (Akarsu, 1998: 44-45). Bu çerçevede kültürel değişimlere uğrayan toplumların sahip oldukları dillerinin de değişmesi tabii bir sonuç olarak değerlendirilebilir. Küreselleşen dünyadaki teknolojik gelişmeler de bu tabii değişimi hızlandırıp neredeyse zorunlu kılmıştır. “...Türkçenin, yabancı dillerin akınına karşı benliğini koruma meselesi, Türklerin İslâm medeniyeti çerçevesi içerisine girdikleri, X. Yüzyıldan itibaren ortaya çıkar" (Öksüz, 2004: 167). Türk milleti tarih boyunca birçok kültürle temas etmiştir. Kültürlerle etkileşim süreci gerek sosyal hayatta gerekse düşünce hayatında çeşitli değişimleri de beraberinde getirmiştir. Söz konusu süreç Türk dilinin farklı birçok kültürle etkileşimi sonucunu doğurarak Türk dilinde çeşitli değişimlere ve gelişmelere kaynaklık etmiştir. Öksüz (2004: 167) sosyal hayattaki değişimin, dille başladığını ifade etmiştir. "Tanzimat ile Batı dillerindeki edebi örneklerin incelenmeye başlaması hayat görüşünün değişmesi yine aynı etki ile milli şuurun yavaş yavaş uyanarak Türkçeyi değiştirmeye başladığı dönemde aydınların karşılaştıkları ilk mesele dil meselesi olmuştur.”

Doğu ve Batının söz konusu kültürel etkileşim süreci Özdemir ve Dağtaş (2014: 28) daha çok bir "medeniyet değiştirme" süreci olarak da nitelendirmiştir. Türk dili bu medeniyet değiştirme sürecinde diğer kültürlerden fazlasıyla etkilenmiştir. Bir toplumdaki siyasî, sosyal, kültürel ve ekonomik alanlardaki değişimler bir diğerine yansır. Toplumda meydana gelen bu türlü değişimler dilde de kendini gösterir ve dili değişken k1lar (Gönülal 2011: 1128). Bu değişkenlik çerçevesinde farklı kültürdeki toplumların dil noktasında birbirlerini etkilemeleri doğal bir mecburiyet olarak değerlendirilebilir. Akarsu (1998: 47) ilerlemeyi dil ile bağdaştırarak, "İnsan türünün geçirdiği bütün ilerlemeler, değişimler dil üzerine etki yapmadan tek tek insanlara, uluslara etki yapmazlar. Bu etkiler ulusların gelişmesinde derinlere kadar işler." şeklinde değerlendirmiştir. Küreselleşen dünya, insan ihtiyaçlarının çeşitliliği gibi durumlar sonucunda dilin aynı kalması mümkün olmadığından, mevcut kelimelerin yeni ihtiyaçları karşılama düzeyi ve yeni kavramları karşılama yolları doğru bir şekilde kullanılarak yeniden değerlendirilmelidir. Bu çerçevede 19. yy'ın son yarısı ve 20. yy'ın başlarından itibaren kültür etkileşiminin dil üzerindeki etkileri, genel olarak "sadeleşme/özleşme/arı Türkçe vb." adı altında çeşitli değerlendirmelere tabi tutulmuştur. Dilimiz ile ilgili önemli problemlerin de bu etkileşime "farklı yaklaşımlardan" kaynaklandığını görmekteyiz. Ayrıca bu değerlendirmelerin kültürel etkileşim var olduğu sürece devam edeceği bir gerçekliktir.

Çalışmanın konusu, Türk Kültürünü Araştırma Enstitüsü tarafından aylık olarak yayınlanan Türk Kültürü Dergisi'nin 1967-1970 yılları arasındaki sayılarında yer alan "dilde sadeleşme ve dil akademisi tartışmaları" ile sınırlıdır. Söz konusu yıllarda sadeleşme ve akademi tartışmalarının yer aldığ 1 hatta akademi konusunda da özel bir sayı çıkaran Türk Kültürü Dergisi, çalışmanın konusu olarak seçilmiştir. Daha önce herhangi çalışmaya konu edilmeyen ve Türk dilinde çok önemli yere sahip aydınların makalelerinin yer alması da derginin üzerinde çalışılması gerekliliğini ortaya çıkarmıştır. Çalışmanın amacı, Türk Kültürü Dergisi'nin 1967-1970 yılları arasında yayınlanan, dilde sadeleşme ve dil akademisi tartışmalarını çeşitli başlıklar altında ortaya çıkarmak ve bunların bir 
değerlendirmesini yapmaktır. Türk Kültürü Dergisi'nin ulaşılabilinen Ocak (1967) sayısından Aralık (1970) sayısına kadar toplam yirmi dokuz sayısı incelenmiş ve tartışmaların içeriğine göre doküman analizi yapılarak başlıklar oluşturulup günümüze $1 s ̧ 1 \mathrm{k}$ tutacak değerlendirmeler yapılmıştır. İncelenen makalelerde herhangi bir ayrıma gidilmemiş dil konusunu içeren her yazı makale konusu çerçevesinde incelenmiştir. Öz Türkçe veya yaşayan Türkçe savunucularının benzer/karşıt her görüşü ele alınmış olup herhangi bir ayrım da yapılmamıştır.

\section{Türkçenin söz varlığı ve dilde sadeleşme tartışmaları}

$X$. yüzyıldan sonra Türklerin İslâm medeniyetine girmeleri sosyal anlamda da birçok değişimi beraberinde getirmiştir. Bu değişimlerin en kaçınılmaz olanı da hiç şüphesiz dil ve edebiyata yansıyan değişimlerdir. İslamiyet'in kabulüyle başlayan dönemde Türkçenin karşısındaki büyük zorluk, yeni dâhil olunan medeniyet çerçevesinde dil ailesi açısından farklı ve edebî kudret seviyesine yükselmiş olan Arapça ve Farsça dillerine karşı mecburî bir mücadeleye girmek zorunda kalmasıdır (Uludağ, 2009: 297). Bu dönemde, Kur'an-1 Kerim'in Arapça olması, Türklerin İslâm dinini Farslardan öğrenmiş olmaları vb. sebepler Türkçe eser veren yazar ve şairlerin söz konusu dillerle olan temasının artmış olduğunu göstermektedir.

Türkçenin tarihî seyri içerisindeki kelime alışverişlerine bakıldığında Köktürk yazıtlarında yabancı kökenli kelimelerin pek az olduğu görülür. "Yerleşik hayata geçiş olarak kabul edilen Uygur döneminde Sanskritten, Çinceden, Soğdcadan ve daha başka dillerden geçme \%2 ile \%5 arası yabancı kelime bulunmaktadır. İslamiyet'in kabulünden itibaren Türkçedeki yabancı unsurlar eserden esere farlılık göstermek üzere artmıştır. Kutadgu Bilig'de \%1.9, Atebetü'l-Hakayık'ta \%20, Yunus Emre'de $\% 13$ bazen \%22'ye kadar artar. Yabanc1 unsurlar Baki'de \%65, Nefi'de \%60, Nabi'de \%54'tür" (Aksan, 2006: 128). Malûm olduğu üzere dünyanın medeni milletlerinin dili "arı" değildir. Her medeni milletin dilinde, dil hazinesi olan sözlüğünde en az \%40 oranında yabanc1 kelime bulunur. Sirp ve Hırvat dillerinde Türkizm adı ile 1965'te Saray'da yayınlanan 660 sayfalık sözlükte Sırp ve Hırvat dillerine Türkçe ve Türkler vasitasıyla geçen 6000 küsur kelime tespit ve izah edilmiştir (İnan, 1968:1).

16. yüzyıldan itibaren özellikle Arapçanın Türk dili üzerindeki etkisi artmıştır. İslam medeniyetinde bilim, tıp alanındaki terimlerin Arapça olması da bu söz konusu etkiyi arttırmıştır. Din alanında yapılan tercüme, şerh ve taliklerde bilim terimlerinin birçoğu Türkçeye geçmiştir (Levend, 2006: 71). Aksan (2006:118) 19. yüzyılda Arapçanın söz konusu etkisinin sürdüğünü ifade ederken Tanzimat ile beraber Batı'dan alınan bazı kavramların da kullanılmaya başlandığını ifade eder. Ana dile giren söz konusu yabancı kelimelerin halk dilinde bulması gereken karşılı̆̆ da önem arz etmektedir. Halkta dilinde (konuşma dilinde) karşıllğı olan kelimelerin özleştirilemeye çalışılması da ayrıca değerlendirilmelidir.

Tanzimat sanatçılarının, çok yönlü olmaları onları amaçlarına ulaşmaktan alıkoydu. Sosyal veya kültürel birçok konuyu birlikte yürütme çabası başlanılan birçok işin eksik kalması sonucunu doğurmuştur. Yapılan işlerdeki kararsızlık ve tereddüt çeşitli fikir ayrılıklarını da beraberinde getirmiştir. Birçok konuda ikiliğe düşen Tanzimat sanatçıları dil konusunda da ikilemde kalmışlardır. "Lisan-1 Türkî mi? Lisan-1 Osmanî mi? Türkçe, Arapça ve Fars dillerinin etkisinden büsbütün kurtulabilir mi, kurtulamaz mı? Kurtulması mümkün olsa da faydalı olur mu olmaz mı?... Tanzimatçıların zihinlerinde yer tutan bu sorular, hiçbir zaman onların hepsinde tam ve ortak cevabını bulamadı. Cevap verenler de ara sıra birbirine aykırı düşen fikirlerini hatta aynı yazıda bulundurmaktan kendilerini kurtaramadılar" (Levend, 2010: 138).

Dilde oluşturulan "tasfiyecilik" hareketi karşısında sadeleşmeyi savunan akımlardan bir tanesi de Genç Kalemler dergisi çevresinde oluşan Yeni Lisan Hareketi’dir. Yeni Lisan Hareketi; Ali Canip, Ömer Seyfettin, Ziya Gökalp imzalı yazılarla başlayan millî edebiyat hareketi, dilde sadeleşme, millî şuur, millî dil bilinci gibi birtakım düşüncelerle ortaya çıkmış, dilin saf ve arı bir şekilde olması için 
çalışmıştır. Yeni Lisancılara göre, Arapça ve Farsça kelimeler söz konusu dile ait dil bilgisi kuralları terk edilince yazı dilinden kaybolacaktır. Yabancı edatlar ve tamlamalar kesinlikle kullanılmamalı ilmi ve fenni terimlere de şimdilik dokunulmamalıdır (Özyurt 2005: 67-69). Dildeki ikiliği kaldırmak; halkın lisanını yazıya aktarma için mücadele eden bu hareketin mensupları tarafından, Türkçe lisanını kullanmanın yeterli olamayacağı ifade edilirken yeni lisanın "ihya" ve "icat"a muhtaç olduğuna da ayrıca dikkat çekilmiştir.

Batılılaşma ile beraber Türk toplumuna benimsettirilmeye çalışılan çeşitli değer yargıları ile dilde sadeleşme tartışmalarının alevlendiği 1960'lı yıllarda Türk aydınları; konuşma dili ile yazı dilinin birbirinden ayrılmış olmasından, terkiplerin uzunluğundan, aşırı süsleme çabalarından, Türkçeye mahsus bir sözlük bulunmayışından, milli dilden uzaklaşılmasından şikâyet ederek dilin 1slah edilmesinin ve sadeleşmenin lüzumuna dikkat çekmektedir. Özel gazeteciliğin başlaması, roman, tiyatro, makale gibi yeni edebi türlerin gelişmesi ve Tanzimat aydınlarının, halkı aydınlatmak için edebiyatı kullanmak istemesi de nesir dilini sadeleşme yoluna koyar (Ercilasun 1980:182, Taş 2002: 89; Özdemir- Yegen, 2013: 325).

Cumhuriyet döneminde Türkçenin geçmişi ve Hint-Avrupa, Avrupa-Asya dilleriyle ilişkileri üzerinde araştırmalar yapılmıştır. Arapça, Farsça kelimelere karşılık bulmak amacıyla halk ağzından ve eski eserlerden yeni kelime türetme çalışmaları yürütülüp radyo ve gazeteler aracılığıyla "öz Türkçe" yazılar yazdırılmıştır. "Dilin doğasının bozulmasıyla özleştirme çalışmaları birçok kelime yerine olmadık kelimelerin kullanılması gerektiği öne sürülmek yoluyla da bir tasfiye etme politikası haline getirilmiştir. Güneş Dil Teorisi, dilin bu çıkmazdan kurtarılmasına yardımcı olur. Böylece Türkçeleşmiş olanın Türkçe kabul edildiği ve Atatürk'ün vefatına kadar sürecek bir dönem başlar" (Levend 2010:395).

İslamiyet'in kabulüyle Arapça ve Farsça, Tanzimat dönemi ile beraber de Batı dilleri ile teması sıklaşan Türkçe; çeşitli kelime veya kural alışverişi ile birbirlerinden etkilenmişlerdir. Sadeleşme; halk tarafından anlaşılmayan yabancı kökenli kelimelerin atılıp yerine dilimizde yaşayan ve herkesçe anlaşılan kelimelerin kullanılması olarak ifade edilebilir. Türkçedeki bu yabancı kökenli kelimeler ve dilde sadeleşme meselesi Tanzimat'a kadar pek kuvvetli değildir ancak daha sonraki dönemlerde sadeleşme düşüncesi yayılarak devam etmiş; üzerinde çalışılan ve çok tartış1lan bir konu olmuştur. Tanzimat dönemi, Osmanlının son yılları, Latin alfabesine geçiş süreci ve Türk Dili Tetkik Cemiyeti'nin kuruluşu yılları ile 1970'li yıllar bu sadeleşme çalışmalarının ve tartışmaların yoğunlaştığı zamanlar olmuştur (Balaban 2015: 577). Ancak bütün bu süreç esnasinda sadeleşme konusunda, "ifrat ve tefrit" hatalarına düşüldüğünden bir orta yol bulunamamıştır. Aslında Genç Kalemlerin başlatmış olduğu "sadeleşme" konusundaki ilkeler ve temkinli yaklaşım daha sonra da sürdürülebilseydi bu konudaki gelişmeler Türk dili açısından daha yararlı ve doğru olabilirdi.

\section{Akademi meselesi}

Akademi kelimesi Yunanca bir kelimedir ve günümüzde; bilim, edebiyat ve sanat konularını tartışmak için bir araya gelen üyelerin oluşturduğu kurullara akademi adı verilmektedir. Dünyanın birçok ülkesinde dil ve edebiyat meselelerini konu edinen akademiler vardır. Bazı akademiler, doğrudan dil ve edebiyat kavramları üzerinde çalışmalar yapmakta, bazıları da daha genel olarak bilimsel, kültürel, edebi ve sosyal çalışmalar yürütmektedir. Dil ve edebiyat alanlarında çalışan akademilerin birçok örneği bulunmaktadır. Almanya'da Berlin İlimler Akademisi, Belçika'da Fransız Dili ve Edebiyatı Kraliyet Akademisi, Çin'de Çin Akademisi, Fransa'da Fransız Akademisi, Yazıtlar ve Edebiyat Akademisi, Goncourt Akademisi ve Mallarme Akademisi, İngiltere'de Britanya Akademisi, İspanya'da İspanya Kraliyet Akademisi, bu akademilerden bazılarıdır (Temir 1968: 71-75)

Söz konusu akademiler arasında, Türkiye'deki dil akademisi çalışmaları için örnek gösterileni Fransız Akademisidir. Çeşitli ilim adamlarından ve edebiyatçılardan oluşturulan bu akademi, kurulduğu yıldan 1932 yılına kadar sözlük tekniği açısından çeşitli çalışmalar yapmıştır. Kelimelerin 
gelişimi-dile nasıl girdiği, halk tarafından yapılan değişiklikler gibi konular bu çalışmalara örnek gösterilebilir (Özdemir- Sügümlü 2013:6).

Çeşitli ilim adamlarından ve edebiyatçılardan oluşturulan yukarıda isimleri sayılan Akademiler, kuruldukları ülkelerde, açıldıkları andan günümüze kadar dil meseleleri üzerine çeşitli çalışmalar yapmışlardır. Bu akademilerin çalışmaları bazı ülkelerde çıkarılan kanunlarla da desteklenmiştir.

Faruk Kadri Timurtaş, (1981: 48-50) Türkiye'de kurulacak akademiyi tarif ederken yapılacak bir yanlışın eskiye dönüş olacağını ifade edip akademi için bazı hususlara dikkat çekmiştir. Fransa'da İlimler Akademisinin varlığından bahsederken aslında "Dil Akademisi" olarak kurulmadığını fakat, "İlimler Akademisi”"nde görev alanlar içinde o dili en iyi kullanan yazar, şair ve aydınların da olduğunu ifade etmiştir. Bu noktada Akademilerin ekseriyetle dil bilginlerinden teşekkül etmesi gerektiğini belirtmiştir. Söz konusu dil bilginlerinin; dilimizi tüm yönleri ile araştırıp eserler vermelerinin hem tarihi hem mukayeseli bir gramer eseri ortaya koymalarının gerekliliği vurgulanmıştır. İlim adamlarının yanında dili iyi kullanan aydınların da olduğu Akademiyi, Türkçe için bir araştırma, geliştirme merkezi olarak tarif etmiştir. Bu merkezin dile giren tüm kelimeler üzerinde söz sahibi olmasının da elzem olduğunu ifade etmiştir.

Bizde ise Dil Akademisi kurulması düşüncesi Türk Dil Kurumunun, siyasi değişmelerden ve iktidarlardan etkilenip çok fazla ideolojik davranmasından kaynaklanmış bir ihtiyaç olarak ortaya çıkmıştır. Dilde sadeleşme çabalarının, siyasilerden çok bu konudaki uzman akademisyen, edebiyatçı ve dilciler tarafindan sürdürülmesini savunanlar dil akademisinin kurulması konusunda çabalar sarf etmişlerdir. Ele aldığımız dönemde ve Türk Kültürü dergisinde bu çabaların nasıl ve kimler tarafindan sürdürüldüğü incelenip değerlendirilmeye çalışılacaktır.

\section{Türk Kültürü Dergisinde yer alan dilde sadeleşme ve Akademi tartışmaları (1967-1970)}

Medeniyet değiştirme süreci İslam medeniyeti ile Batı medeniyeti arasında kalan Türk toplumunun dilini de derin ve kalıcı bir biçimde etkilemiştir. Batılılaşma sürecinde, dilimize giren kelimelerden ziyade, genellikle Arapça ve Farş̧adan alınan kelimelerin sadeleştirme/özleştirme çerçevesinde değerlendirilmesi ayrıca dikkat çekicidir.

Yaptıklarını "arı Türkçe" veya "öz Türkçe" olarak adlandırıp özleştirme meselesini "devrim" çerçevesinde değerlendirenler ile "yaşayan Türkçe"yi savunarak "millî dil"e hizmet ettiklerini söyleyenler de bunu "Türkçe" adına yaptıklarını iddia etmişlerdir. Söz konusu dönemdeki siyasi manzara ve Batı merakı; birçok kültürel değerin yargılanmasını veya yok edilmeye çalışılması sonucunu doğurmuştur. Bu yargılanma ve yok sayma da Türk diline yansımış olmakla beraber "Dilde Sadeleşme ve Dil Akademisi” tartışmalarını da beraberinde getirmiştir. Türk Kültürü Derneğinin 1967-1970 yılların arasında çıkardığı Türk Kültürü dergisi yukarıdaki görüşlerden "Yaşayan Türkçe"yi savunarak "milli dil"e hizmet etmeyi amaçlamas1 ve mücadelesini bu yolda sürdürmesi bakımından dikkat çekmektedir. Aslında bir dil ve edebiyat dergisi olmamasına rağmen Türk Kültürü dergisi dil tartışmaları konusuna ilgisiz kalmamış, yukarıda da ifade edildiği gibi dergide, "yaşayan Türkçe" anlayışı çerçevesinde fikirler savunulmuştur. Özellikle yabancı kökenli de olsa halkın kullandığı ve anlamını bildiği kelimelerin kullanılmasında bir sakınca görmeyen bu anlayış, gereksiz ve yanlış kelime türetilmesine karşı çıkmıştır. Bu şekilde gereksiz ve yanlış türetilen kelimelere "uydurukça" denilerek itiraz edilmiştir. Bu itirazlar dönemin en şiddetli tartışmalarına da kaynaklık etmesi açısından dikkat çekicidir.

\section{Uydurma kelime meselesi}

Kelime türetme konusunda Türk Kültürü dergisinde 1911'de Genç Kalemler dergisinde savunulan ve Ziya Gökalp'in "Türkçeleşmiş Türkçe" diyerek isimlendirdiği anlayışa benzer bir anlayış savunulmaya devam edilmiştir. Abdülkadir İnan, "Bazı Yeni Kelimeler Üzerine Düşünceler” 
başlıklı yazısında "arı dil" taraftarı dediği ve "dilde devrim yapıyoruz" diye ortaya çıkanları şu cümlelerle eleştirir:

"Bizim "arı dil" taraftarlarının çoktan Türkçeleşmiş Arapça ve Farsça kelimelere karşılık olarak, "arı Türkçe" diye teklif ettikleri kelimelerin bir kısmı bin yıl önce Türkçeleşmiş yabancı kelimelerdir. Arı dil yapmanın "kelime" yerine "sözcük" demekle yapılamayacağını anlamak lazımdır. Türk dili üzerine çalışan kurumlarımız Batıl dilcilerin yaptıklarından ve metodlarından habersiz olduklarından her kelimeye karşıllk bir sözcük uydurmayı marifet saylyorlar." (İnan, 1968:3)

Buna karşıllk Türkçeye her gün yeni yabancı kelimelerin girdiğini ifade eden yazar en çok okunan gazete ve dergilerin bir haftalık yayınlarından gelişigüzel topladığı şu kelimeleri örnek olarak verir: "absurd, montaj, motif, mozaik, fiş, dekor, aktul, aktif, passif, organ, televizyon, kanten, sentez, sempati, sivil, analiz, üniforma, orijinal, naif, ideal, real, kriz, karakter, problem, metod, aksiyon, melankoli, kategori, antipati..." İnan, asıl yapılması gerekenin, Türk milletinin asırlardan beri kullanıp yaşattığı kelimeleri yabancı kökenli diye atmak yerine yukarıda bir çırpıda saydığı ve Türkçeye girmekte olan kelimelere karşılık bulunması olduğunu savunur. Aslında burada da görüldüğü gibi dilimize yabanc1 dillerden girmekte olan kelimelere karşılık bulunması konusunda "arı Türkçeciler" ile "yaşayan Türkçeciler" aynı şekilde düşünmektedir. Bu ortak düşünceye rağmen ayrıldıkları nokta ise; “Türkçeleşmiş Türkçe”ye karşı takınılan tavırdır. İnan, bu konudaki eleştirilerine şu cümlelerle devam ediyor:

Dilde devrim yapıyoruz diye Türk milletinin asırladır kullanıp bugün de yaşattığ kelimeleri atıp yerlerine kimsenin anlamadı̆̆ özgür, uygar, koşul gibi kelimeler uyduran bizim "dilciler" "medeniyet, hürriyet"i devrim köprüsünden geçirmemek için direniyorlar amma her hafta Türk yazı diline binlerce kelimenin girdiğinden haberleri yok" (İnan, 1968:4)

Türkçeleşmiş Türkçe olarak ifade edilen kelimelerin, "devrim yapıyoruz" denilerek dilden atılmasına ve milletin hafizasından silinmesine karşı çıkılan bu ifadeler kültürel birikimlerimizin kuşaktan kuşağa aktarılması noktasında önem taşımaktadır. Zira bu kelimelerin yok sayılması, milletin gelenek-göreneklerinin, yaşayışının, günlük hayatının ve olayları milli-manevi bir biçimde değerlendirme hassasiyetinin engellenmesi ya da yok edilmeye çalışılması ile eşdeğerdir. Buna karşılık yapılması gereken ise, "her hafta Türk yazı diline binlerce kelime girişine" engel olmaktır.

Bu kelimelerin sadeleştirilmesi veya tasfiyesi, artık üzerinde çok fazla durulması gereken bir mesele olmamalıdır. Türkçeye yerleşmiş bir "Allah" sözünü Arapça diye atıp yerine tanrı kullanmaya kalkarsanız, günlük konuşmalarımızda kullandığımız "inşallah, maşallah, Allah Allah, Aman Allahım, Allah kahretsin" gibi birçok ifadeyi de dilden atmış veya anlamsız hale getirmiş oluruz (Balaban 2015: 583). Milletin hafizasına yerleşmiş bu ve buna benzer daha birçok kelimenin değiştirilmeye çalışılması bin yıldan fazla geçmişi olan Türk milletinin; dilinin ve kültürünün yok edilmeye başlanılması olarak değerlendirilmektedir. Osmanlı'da başlayan reform süreci, ihtiyaçlar doğrultusunda Batı'nın karşısında geri kalmışlıkla belirlenmiştir. Çoğu noktada, Batı modernleşmesine bir karşı duruş olarak da ortaya çıkan bu süreç, gerekli noktalarda Batı'yı örnek aldı. Bu çabalar bazen ordunun modernleştirilmesi, bazen eskiye olan özlem, bazen de Batı karşısındaki ezikliğin bir ifadesi olarak karşımıza çıkmıştır (Rosay 2006: 92). Bu çerçevede aydınların medeniyet değiştirme çabaları dildeki karşılığını, "sadeleşme çabaları olarak" bulmuştur. Ancak, milletin tarihi hafızasında yer alan ve her biri Türk milletinin kültüründen izler taşıyan kelimeleri yok etmeyi medeniyete geçiş olarak görüp dilde "sadeleşme" çerçevesinde sunmaya çalışmışlardır. Avrupalılar kendinden olmayan veya olmasını istemedikleri toplumları en çok "medeniyet" (civilisation) anahtar kelimesiyle ölçerek değer biçmiş̧lerdir (Yetişgin 2005: 52). Aşırı bir şekilde cereyan eden bu geliş̧melere bağlı olarak Batı ile temasın, bir "alafrangalık" modası doğurduğu ve bu defa Türk dilinin yeni bir salgının tehdidi altına 
girdiğini söyleyebiliriz. Hâlbuki Doğu medeniyet ve kültürünün ağır baskısından kurtularak, tarihi hayatı içinde temiz, duru, çekici bir güzelliğe bürünen dilimizin kapıları, Batı dillerinin istilasına açılmakla hedefe ulaşılamayacağ 1 açıktır. Bir yenilik karmaşasıyla yapılan böyle bir harekete, dil ve kültür hayatının feda edilemeyeceği gerçeğinin çok defa görülmemesi talihsizlik sayılmalıdır (Öksüz 2004: 14)

Bu konu ile ilgili olarak, Türk milletinin hafızasının uydurma kelimelerle değiştirilmesi ve diğer Türk toplulukları ile arasındaki bağın ortadan kaldırılması çalışılmalarının 1930'lu yıllardaki yansıması Ercilasun tarafından şöyle ifade edilmektedir:

"Taşkent'li Özbek Türk'ü "edebiyat, nazariye, cemiyet, terakkiyat, ehemmiyet, tasvir, vasita, eser, tahlil, kanuniyet diyor; "yazın, kuram, toplum, ilerleme, önem, betimleme, araç, yapıt, çözümleme, yasalılık” demiyor. Bakü'deki edebiyat profesörü "edebiyat, inkişaf, mühim, sair, eser, hususen, samimi, mukaddes, samimiyyet, şahsi, menfaat, ummumi" diyor; "yazın, gelişme, önemli, ozan, yapıt, özellikle, içten, kutsal, içtenlik, kişisel, çıkar, genel" demiyor" (Ercilasun, 1980:55).

10.yüzyılda Arapça ve Farsça ile başlayan sonrasında Fransızca günümüzde ise İngilizce'nin etkisinde gelişen dış etkiler sonucu olarak başlayıp devam eden sadeleşme sürecinin, her milletin yaşadığı değişim ve gelişim sürecinde yürütülmediği Ercilasun'un ifadelerinden de anlaşılmaktadır. Ercilasun, "uydurmacılık”ın nesiller arasındaki bağı nasıl kopardığını, Şekspir ve Atatürk'ün Gençliğe Hitabesi üzerinden yaptığı benzetme ile ayrıntılı bir şekilde şu cümlelerle ifade etmektedir:

"Ders kitaplarındaki kelimeleri bir iki yıl içindeki her baskısında değiştiren yazarlar vardır. (...) SSekspir' in eserleri Ingiltere'de asla sadeleştirmeye ihtiyaç duyulmadan, orijinal dili ile bastırlmakta, tiyatrolarda da daima orijinal dili ile temsil edilmektedir. 16. asırda yaşamış bulunan Şekspir' in kelime kadrosunun hemen hemen tamamı bugünkü Ingilizcede de kullanllmaktadır. Şimdi size Atatürk'ün Gençliğe Hitabesindeki istatistik bir neticeyi sunmak istiyorum. 1927 yllinda irad edilen bu nutuk, 1964 yılında yani 37 yll sonra TDK tarafindan "Söylev" adıyla "bugünün Türkçesine çevirtilmiştir. "Ey Türk Gençliği" hitabıyla başlayan kısminin Atatürk'ün ăgzından çıkmış şekli, "ve”ler hariç 155 kelimedir. 37 yll sonra Söylev'de bu 155 kelimenin 79 tanesi değiştirilmiştir. Değiştirilen kelimelerden bazılarını örnek olarak veriyorum: İstiklâl-bağımsızlık, ilelebet-sonsuzluğa değin, hazine-güven kaynăgl, bedhah-kötücül, imkân-olanak, şerait-koşullar, galibiyet-utku, aziz-sevgili, zaptedilmiş-alınmış, tersanegemilik, gaflet-aymazlı, emel-erek, evlât-gençlik, ahval-ortam, dahi-bile, asil-soycul. Görüldüğ̈̈ gibi eski sayllan kelimelerin karşılıkları yerine bazan tamamen değişik mânâdaki kelimeler konmuştur. "Hazine", "kaynak" demek değildir. "Aziz'in karşıllğı "sevgili" midir? "Zaptedilmiş ile "alınmış" aynı mânâda olabilir mi? Hele "Ey Türk istikbâlinin evlâdı!"ndaki "evlât" yerine "gençlik" kelimesini koyarak "Ey Türk geleceğinin gençliği" demek nasıl olur? Söylevciler "mahiyet" ve bilfiil" kelimelerini ise tamamen atmışlar, yerlerine hiçbir şey koymamışlardır. Özbeöz Türkçe olan "dahi kelimesini de yabancı zannetmişler ve "bile" ile değiştirmişlerdir. (...) Türk aydınları, 37 yıl içinde Atatürk'ün hitabesinin yarısını anlamaz hale gelmişler veya öyle kabul edilmektedir. Ingiliz aydınlar ise 400 yll önceki Şekspir'i hemen hemen tamamıyla anlamaktadırlar" (Ercilasun, 1980:58).

Kelimelerin anlam inceliklerine dikkat etmeden yapılan bu zoraki değişiklikler, 37 yıl gibi çok kısa bir süre içerisinde birbirini anlayamayan kuşakları, dolayısıyla toplumda kültürel bir kopmayı ortaya çıkaracağ 1 ifade edilen bu satıllar dikkat çekicidir. Türk Kültürü dergisinde "uydurmacılık" meselesinin dış Türkler boyutuna da dikkat çeken değerlendirmeler yapılmıştır. Arapça ve Farsçadan dilimize geçerek "Türkçeleşen" kelimelere karşı takınılan tavır, bir "savaş dili" olarak ifade edildikten sonra Azeri bir gazeteci yazardan şu alıntı yapılmıştır: 
“ - Men Türkçenin bu hale gelmesine çok müteessir olmuşam. Siz dünyadaki Türklerin birbirinden gopmasına sebep olursuz! Iran'da 12 milyon, Rusya'da gırk milyon Türk var. Bunlar sizin uydurduğunuz kelimeleri anlamırlar. Radyolarınızı dinlemirler kitaplarınızı okuyabilmirler. Vazgeçin bu tahribattan.” (Felek, 1969:13).

Azeri yazarın bu ifadelerinden hareketle "uydurmacılı̆̆ı", dilimizi belli bir diyarda az bir zümrenin lehçesi haline getirdiği ve belki de bu dili kelime uyduranların kendilerinin bile anlamadığı, daha da önemlisi Türk dünyasının birbiri ile anlaşamayacağı yorumları yapılmaktadır. Ayrıca, halkın anlamadığı ifadelerle sürdürülmeye çalışılan sadeleşme sürecinin söz konusu yıllarda masum bir sadeleşme olmadığı da vurgulanır.

Türklerin birbirlerini anlamaması demek; yüzyıllar boyunca bir olmuş, aynı şekilde nefes almış, dünyaya varlığını cesaretini / kahramanlığını kanıtlamış ve dünyaya umut olmuş bir milletin hafızasının silinmeye çalışılmasıdır. Türk kültür ve mirasını yok etme çalışmaları "dilde sadeleşme/özleşme” kisvesi altında sunulmuştur denilebilir. Nitekim milletin hafızası ile tarihi kimliği ile oynamak her Türk kavmini bulunduğu coğrafyaya hapsetmeye çalışmak sadeleşmeden ziyade daha çok İslamiyet ile bir bütün olan Türkleri yok etmeye çalışmak dişında ne ile açıklanabilir. Bu yok etme sürecinin bir diğer kanıtı da Türkçeleşmiş kelimler yerine önerilen kelimeler üzerinden nasıl yapıldığı Abdülkadir İnan tarafından dergide şöyle ifade edilmiştir:

"Yeni kelimeler arasında en çok dikkat çekeni kutsal kelimesidir. 8.asırdan beri manasında değişikli olmayan "kut" kelimesinden, uydurma -sal eki ile "mukaddes, kudsi” kelimelerinin karşıliğı olarak kabul edilmiştir. Bunlardan başka; şeref, meselâ, işaret, hayal, remiz, cihan, âlem, dünya ve kâinat kelimelerine de bir sürü uydurma veya eski kelimeler karşılık gösterilmiştir. "Mesela” kelimesi bin yıl önce Türkçeleşmiştir ki, halk dilinde bile mevcut olan bir kelimedir. Ermenice kökenli “örnek” kelimesi ne kadar Türkçeleşmişse "mesela” kelimesi ondan daha fazla Türkçeleşmiş bir kelimedir. Bu durumlar Türk dili devrimcilerinin Türkçeyi Fransızcaya benzetme gülünçlügünden başka bir şey değildir” (İnan, 1968:4-5).

Söz konusu değişiklik çabası dönemin aydınlarının Fransa'da aldıkları eğitimi ve Fransız kültürünü; Türk milletinin ve bu milletin değerlerinin nasıl üstünde gördüklerinin kanıtı olacak niteliktedir. Kendi kültürünü ve kimliğini hiçe sayarak, 8. asırdan beri dünyadaki tüm Türkler tarafından kullanılagelen bir kelimenin yerine sadece özleştirme mantığıyla kelime önermek bizi biz yapan değerlerden uzaklaştırmaya çalışmaktır. Günümüzde okullarda dolayısıyla ders kitaplarında "mukaddes, kudsi, cihan, âlem" gibi daha birçok kelimeye "yabanc1 kelime" muamelesi yapılmaktadır. Söz konusu kelimeler cihana hâkimiyet kurmuş bir milletin kültüründen süzülerek ve Türk milletine mâl olmuştur. Ayrıca Türk Kültürü dergisinde Burhan Felek (1969) yeni bir kelimenin nasıl önerilip değerlendirilmesi gerektiğini tarif ederken "Akademi" kurumunun etkisini de ifade etmiştir.

"Fransızcada "gemi karaya inme, uçak yere inmek" anlamalarına gelen "atterir" sözcügüne benzetilerek son zamanlarda "alunir" (aya inmek) anlamında bir sözcük kullanılmaya başlanmıştır. Bu kelime yerine hiçbir kelime atılmadan hem de dile yeni bir kelime kazandırmak maksadıyla bu fiil ortaya atılmıştır. Bütün bunlara rağmen Fransız Akademisince kabul edilmemiştir. Akademi: "Atterir" "karaya inmek" manasına geldiğinden ve Ay da umumi yapısı itibarıla kara parçası olduğundan aynı fiil "aya inmek" manasiyla da kullanilabilir. Usulüne tamamen uygun olsa da keyfi şekilde kelime türetilemez. Hacıeminoğlu: "İşte Fransa'da dil hadisesi böyle ele alınmakta gel de bunu bizim ehliyesizler saftast ile mukayese et.” (Felek, 1969: 39-42)

"Öz Türkçe” yanlıları hiçbir kural tanımayarak kelime üretirken, Türkçeyi yabancı dillerin etkisinden kurtardıklarını ifade etmişlerdir. $\mathrm{Bu}$ durumun yanlışlığı: Osmanlı Türkçesinde 
kullanılmakta olan Arapça ve Farsça kelimeler yerine Fransızca, Latince veya İngilizce karşılıklarını yerleştirme çabaları ile ifade edilebilir. Türkçeyi yabancı bir dilin etkisinden kurtarmaya çalışıp başka bir yabancı dilin boyunduruğu altına sokmanın "özleştirme" olarak izahı pek de mümkün değildir. Dilaçar, bir dilin özleşmesinin temel şartının dil haznesinde yer alan kelimelerle ve mümkün olduğunca milli söz kaynaklarından alınan dil kuralları ile mümkün olabileceğini belirtmiştir (Dilaçar 1948- Akt. Erciyas 2010: 1191).

İlhan Çeneli, A.Sırrı Levend'i örnek vererek "öz Türkçe” yanlılarının kendi içlerinde nasıl bir çelişkiye düştüklerini şu şekilde eleştirmiştir:

"Hakikat" kelimesini kullanıyorsanız bir yazınızda, "Osmanlıcacl" (Dil devrimi düşmanı) oluverirsiniz. "Mecburiyet, ikaz, inşâ, rağmen" kelimelerini kullanıyorsanız "koyu Osmanlıcacı" siniz. Ama bir nokta unutulmamalıdır. Bu kelimeleri kullanip TDK' yı tenkid etmiyor iseniz "Osmanlıcacı" olmazsınız. Tıpkı Agâh Sirrı Levend bey gibi.

Levend eserlerinde ve yazılarında şu kelimeleri rahatlıkla kullanmaktadır: şâir, hayat, kitap, edebiyat, bahis, kelime, tesbit, halbuki, zahmet, şekil, işâret, esas, tasavvufi, vücut, irşad, meclis,zevk, dini, hikâye, akıl, imtiyaz, şüphe...

TDK bu kelimelerin hepsine öz Türkçe saydı̆̆ yeni karşılıklar bulmuştur. Levend bu karşıllkları kullanmadı̆̆ halde Türk Dil Kurumu ona niye "Osmanlıcacı" diyememektedir. "Öz Türkçe ülküsüne varmak" isteyen A.S. Levend bu yeni kelimeleri niye kullanmamaktadır? Kullanmamasının sebebi bu kelimelere uygun karşılık olmamasından ise, bunlart ortaya atanları neden uyarmamıştır? "Dilimize giren her yabancı kelimeyi uygun karşıllk bulmadan atamayız." diyen A.S. Levend bey, dediğinin tam tersini yapanları uyarmamakla onlara yardımcı olmuş olmuyor mu? Ĕger bu karşıllıklar tam ise, bunları kullanmamakla "öz Türkçe” ye varılmasını güçleştirmiş, geciktirmiş olmuyor mu? Buradan da anlaşllacağı üzere TDK kendini tenkid edeni "Osmanlıcacı", "dil devrimi düşmanı" yapıvermektedir" (Çeneli, 1969:42).

“Öz Türkçe” hareketinin "öz” olamadığı ve uydurulan kelimelerin aslında başka maksatlarla Türkçeye sokulmaya çalışıldığı Agah Sırrının kullanımları ile kanıtlanmaktadır. Nitekim en az bin yıllık olan Türk kültüründen süzülmüş, ortak heyecanı, ülküyü yani Türk milletini yansıtan kelimelerden toplumu soyutlamaya çalışmak mümkün gözükmemektedir. "Öz Türkçe" akımını savunan Agâh Sırrı Levend bile anlatmaya çalıştığı ifadeyi karşılayacak kelime bulamamış olacak ki, Türk toplumuna mâl olmuş kökeni farklı olsa da artık Türkçeleşmiş ve Türkçe olan kelimeler kullanmıştır. Günümüzde; geçmişinden ve köklü kültürünün yüceliğinden ortaya çıkmış kelimelerin, anlamlarının bilinmeyişi veya yabancı kelime olarak görülmesi Türk evlatlarının o köklü kültürden kopuk olmasına, diğer birçok kültürün esiri olması sonucunu doğurmuştur. Geçmiş̧ten günümüze eski olanın değersiz olarak gösterilmesi, köklü olanın Türk milletine mâl olanının geri kalma sebebi olarak sunulması bu sonuçlardan en acı olanıdır. Levend' in tavrını eleştiren İlhan Çeneli, dil meselesinin aynı zamanda bir kültür meselesi olduğunu ve bu sorunun çözümünü aynı makalede şu şekilde ifade etmiştir:

"Dilimizin içinde bulunduğu buhrandan kurtulabilmesinin tek yolu onu, dilcilerin eline birakmaktır. Dilciler dili inceleyecekler araştırmalar yapıp elde ettikleri malzemeyi dilin asıl yaratıcıları olan şair ve yazarlara bırakacaklardır. Dil meselesi çözülmedikçe kültür meselesi de çözülmeyecektir. Dil meselesini çözmeden hiçbir şey yapılamayacağını bilmemiz bu meseleye olan yaklaşımımızı da çok önemli kılmaktadır" (Çeneli 1969:44) 


\section{TRT'nin dili}

Bir toplantıda Azerbaycan Başbakanı "Bakın sizinle ne güzel konuşup anlaşlyoruz. Fakat nedense Ankara radyosunun dilini anlamıyoruz." diyor. Karşıllk olarak Sanayi Bakanı "Ekselans merak etmeyin, onu biz de anlamıyoruz." diyor.

Radyonun dili budur onu içerde de dışarıda da kimse anlamıyor ve sevmiyor. Hassas günlerde radyo başında ajansı dinleyenlerin söylenenleri anlamak için mektepli birini aradıklarını kaç kez tanık olmuşluğum vardır ki bu dili mektepli de mektepsiz de anlayamaz. Asl esasi olmayan bir dilin ise, tam olarak bir mana taşımasina ve anlaşılmasına elbette imkân yoktur. Onun için Türk milleti dilini tam olarak değil mealen anlamaktadır (Ergin, 1969:1).

Sadeleşme sürecinin gerçek boyutunu göstermesi bakımından Ergin'in (1969) aktardıkları oldukça önemlidir. Öz Türkçe yanlılarının sadeleştirme sürecinde takındıkları "yok sayma" politikasının yansımaları TRT'de vücut bulmuştur. Dönemin siyasi koşulları neticesinde bu "yok sayma" politikasını işletecek olan kişilerin TRT gibi etkili bir kuruluşta görev almaları düşündürücüdür. $\mathrm{Bu}$ kişilerin milliyetçilik anlayışları, hayat görüşleri ve dünyadaki Türk topluluklarına bakış açıları, anlaşılamayan bir radyo dili ile açığa çıkmış olmaktadır. TRT'de icra edilen dildeki bu aşırı özleştirme çabasını "yabancı dillerin etkisinden kurtulma" olarak değil de daha çok kültürel yozlaşma, Türk kültürünü ortadan kaldırma ya da Türkler arasındaki milli ve manevi bağı koparmak olarak almak gerekmektedir. Zira bu derecedeki bir özleştirmenin; Türkçeyi düşünmek ya da yabancı kelimeler yerine Türkçe kelimeler koymak şeklinde açıklanması mümkün gözükmemektedir. Dönemin en etkili silahı olan radyo, uydurma kelime ve Türkçeye zarar vermek için öz Türkçeciler tarafından adeta bir karargâh haline gelmiştir. Muharrem Ergin ve Burhan Felek (1969) söz konusu değişim sürecinin yanlışlığını ve olmazlığını şu şekilde değerlendirmiştir:

"Radyonun bu bozuk ve zevksiz Türkçesinin tek işe yarayan tarafi iyi bir kötü örnek olmasidır. Bizler kötü ve yanlış konuşma örneği misallerini çoğu defa radyodan alırız. Uydurma kelime ve devrik cümle memleketi kasıp kavuran uydurma dil içerisinde iki kötü cephedir. Uydurmacıllk deyince sadece kelimler üzerinde durmak adet olmuştur. Bu doğru değildir devrik cümle kullanımı daha tehlikelidir. Uydurma dil, öz Türkçe, arı dil şüphesiz TRT den doğmuş değildir. TRT'ye bulaştırılmıştır. Radyonun tesirini bilen uydurmacılar bir kolayını bulup TRT'ye yerleşmişlerdir. 1960 ihtilalinin yanlış yorumlanmasından istifade eden solcularla mücerrit uydurmacılar birçok kilit noktada olduğu üzere radyonun dil politikasını da ele geçirmişlerdir" (Ergin 1969:3).

"Bir de radyoda bir okuyucumuz tarafindan duyurulan, "toprağ bol olsun" ifadesinin müslim biri için kullanılması da kesinlikle vurdumduymazlıktır” (Felek, 1969:14)

Bireylerin zihinlerine, radyo ile yeni diye tabir edilen kimsenin anlamadığı kelimeleri sunmak milletin algısını değiştirmeye çalışmaktır. Aynı zamanda etkili bir yayın organı olan radyoda bu şekilde bir yayın yapılmasına müsaade etmek ya da müdahale edememek düşündürücüdür. Nitekim yukarıdaki bölümde ifade edildiği üzere Sanayi Bakanının: “ - Ekselans merak etmeyin, onu biz de anlamıyoruz." Demesi, durumun çaresizliğini göstermesi açısından ehemmiyetlidir. Meselenin "Türkçeleştirme" olmadığı da aşikârdır.

Hedef sadece bir kelime operasyonu değil, lûgat mes'elesi yani yabancı menşe'li kelimelerin terk edilip yerlerine şu veya bu yeni ve başka kelimelerin konulması işinden ibaret değildir. Daha ileri hedef, bunun da ötesinde ilk kademede dili de değiştirerek, yeni nesillere yabancılaştırarak bu dilin aracılık ettiği ana kültürü aradan kaldırmak, saha dışı bırakmak, onun yerine kendi dilini de beraberinde getiren, müesses kıymetleri değiştiren bir başka dünya görüşünü ve onun kültürünü yerleştirmektir. Dava bu noktada formülünü bütün vecizliği ile bulur, ortaya vurur: Yeni bir dil, yeni 
bir nizam... Yeni bir nizam için yeni bir dil!..” (Akün 1981: 37- Akt. Gönülal 2012: 165). değerlendirmesinin yapılması, durumun vahametini göstermesi açısından dikkat çekicidir.

\section{Ek meselesi}

Keyfî, ilmî temelden yoksun olmanın bir diğer yansıması da uydurma kelimelerin yapılmasında kullanılan ekler meselesidir. Abdülkadir İnan bu eklerin yanlışlığını şu şekilde izah etmiştir:

-al, -sal, ve -ik ekleri de değerlendirilir. - al ekinin "öz Türkçe” olduğunu iddia edenler de oldu. Söz konusu ek (-al) Fransızcadan alınmış olup yanında bir de-sal eki uydurulmuştur. Bu eklerin ne gibi kelimelere hangi kaidelerle ekleneceği belli değildir. Bir kelimeden nisbet sıfatı teşkil etmek için -al mi yoksa -sal mı gelecek belli değil, söyleyenin keyfine bağlıdır. Niçin tarımsal da tarımal değil, niçin duysal da duyal değil niçin küresel de kürel değil? (İnan, 1969:5).

Kıvanç Demir, TDK dergisinde (1968) çıkan bir yazısında Abdülkadir İnan'1, - sal, - sel ekinin kullanımı ile ilgili eleştirmiştir. Demir'e, bu konu ile ilgili cevap İlhan Çeneli tarafından şu şekilde verilmiştir.

Kıvanç Demir şu satırları yazabilmektedir: "İçlerinden biri de çıkıp yapılan yanlışlıklar, aksaklıklar varsa bunu göstermeye, iyiyi, daha güzeli yaratmaya yanaşmıyor." Demir bu satırlarında haksızıdır. Bugüne kadar pek çok kimse onların bu yanlıştan dönmeleri için birçok defa yazı yazmıştır. Bu tenkitlerden faydalanmadıkları şu şekilde aşikârdır.

K.Demir, -el ekiyle üretilmiş yeni kelimler vermiş; bölgesel, ezgisel, içgüdüsel, kamusal, kılgısal, töresel, kişisel... Bu kelimelere getirilen ekler için Demir: “Aldülkadir INAN, -l ve -sal eklerinin kullanma kaidelerinin olmadığını ifade etmiştir. Oysa bunun kuralı kendiliğinden belirlenmiştir. Örneğin, sonu ünlü ile biten sözcüklere -l eki getirilir: yasa-l, doğa-l gibi. Sonu ünsüzle biten sözcüklere ise-sel, -sal eki getirilir: bilim-sel, toplum-sal, birey-sel gibi.

Sonu ünlü ile bitenlere -l eki getirilir diyen Demir, bir ay önceki yazısında gösterdiği "bölgesel, ezgisel, kamusal, içgüdüsel, töresel, kişisel kelimelerinin yanlışlığını ortaya koymuyor mu? Çünkü bu kurala göre kelimelerin: "bölgel, kişil, ezgil, içgüdül, kamul, törel olması gerekirdi. Demek ki asıl yanıltmaca K.Demir tarafindan yapılmaktadır (Çeneli, 1969:40-41).

Söz konusu yanıltmacanın dilde özleştirme adı altında yapılıyor olması da ayrıca dikkat çekicidir. Yeni oluşturulan kelimelere getirilen ekler, fonksiyonu ve anlamı doğru ise kullanılmalıdır. Aksi halde oluşturulan kelimler "uydurma kelimler" olarak ortaya çıkmaktadır. Sadeleşme yanlılarının Arapça ve Farsça kelimler olmasın ne olursa olsun mantığı ile yaklaştıkları İnan (1969) tarafindan yapılan değerlendirme ile de ortaya çıkmaktadır.

SíSAV seminerinde Timurtaş (1980 Akt. Özkan 2013:329) sadeleşme işinin çıkmaza girmesinin sebebini, halkın yeni kelimeleri beğenmemesine bağlamaktadır. Söz konusu yeni diye üretilen kelimelerin gramer ve șekil bakımından yanlıș olduğu, isme getirilmesi gereken ekin ek fiile, fiile getirilmesi gereken ekin ise ek isme getirildiğini ifade etmiştir. Böylelikle anlamı ve grameri yanlış olan kelimeler "öz Türkçe" olarak sunulmuştur diye ifade etmiştir.

Dilimizde nisbet ifade eden bir "-sal, -sel" eki bulunmadığı halde bu eklerle yapılan kelimler meydana getirilmektedir. Söz konusu ek bazen "-al, -el” bazen de "-l” şekline girmektedir. Bunlardan "-al, -el” Fransizca "-sal, -sel ve -l" ekleri ise uydurmadır. Dilimizde öyle nispet ekleri yoktur (Timurtaş 1980: 25). 


\section{Akademi tartışmaları}

Türkiye’de dil akademisinin oluşturulması şüphesiz gereklidir. Bu meseleyi Köymen (1968: 45) şu şekilde özetlemektedir: "Devlet kendi akademisini kurmalı, Türk dilini gayrı mesul şahısların keyiflerine göre işledikleri bir konu olmaktan kurtarmalı ve okullarda öğretilecek Türkçeyi kendi akademisi vasıtasıyla tespit etmelidir." Söz konu keyfiliğin boyutları sadeleşme adı altında yapılanlarla açıkça görülmektedir. Milli kültürün hiçe sayılması, üzerinde yaşanılan toprağı "vatan" yapan unsurların özleştirme adı altında yok edilmeye çalışılması; manevi kalkınmayı sağlayacak olan ruh ve beden ahengini ortadan kaldırmaktadır. Günümüzde özellikle de okullarımızda yarınlarımız olarak ifade edilen neslin büyük bir kısmı milli ve manevi değerlerden yoksun "Türkçe" konuşamadığ gibi ne söylediği de anlaşılamayan bir durumdadır. Köymen’in (1968:5) aşağıda yer alan tespitinin ruh beden ahenginin bozulma sebebini göstermesi bakımından önemli olduğu düşünülmektedir.

“Türk milleti kadar kendini ve kendi kültürünü ihmal eden başka bir millet gösterilemez. Yalnız ihmal değil, gayri mesul şahıslar ve müesseseler tarafindan kendi kültürünün ihmal edilmesine ve bozulmasına, göz göre göre, müsaade eden başka bir millet yeryüzünde zor bulunabilir. Mesela, işlene işlene bütün dünya Türklügünün müşterek bir kültür dili haline gelmiş olan Türkçenin bozulmasına ve Türkiye sınırları dışında hiç kimsenin anlayamadı ̆̆g, hatta milli sınırlar içinde yaşayan muhtelif yaşlardaki insanların bile birbirleri ile kolayca anlaşamadıkları bir mahalli lehçe haline getirilmesine, dünyanın neresinde hangi, millette müsaade edilir?” (Köymen 1968:5).

Kültür meselesinin ihmali ve bir milletin geçmişi ile olan bağının ortadan kaldırılmaya çalışılması, o milleti topyekûn yok etmektir. Bu yok olmanın dilde başlatılıyor olması ve bu duruma herhangi bir müdahalenin de yapılmıyor olması ayrıca dikkat çekicidir. Bu bağlamda bir milleti millet yapan unsurların korunması noktasında mihenk taşı olabilecek bir kuruma karşı çıkmanın ilmi bir izahı da mümkün gözükmemektedir. Bu konudaki görüşleri derleyen Tevetoğlu, (1968: 24-32) dönemin bazı aydınlarının akademi kurulması konulu ankette yer alan görüşlerini şu şekilde aktarmaktadir:

Avram Galanti Bey: "Bütün ilim kolları bizde lâyıkı vechile gelişmemiş olduğundan: "Hal-i hazırda hakiki ilmi bir tecanüs mevcut değildir. Binaenaleyh, bu şeriat tahtında teşekkül edecek akademinin muvaffakiyetle iş göremeyeceği tabiidir." Kanaatini savunmaktadir.

Burhan Cahid Bey: "Akademiye luzüm yoktur ve inklap nesli tabii menba'lardan toplanmış yeni ve hakiki san'at eserleri yaratıncaya kadar bu mesele mevzubahis olmamalıdır." diyerek kesip atmaktadır.

Hıfzı Tevfik Bey: "Akademi irfan hayatını tanzim için gerekli olsa da ilim ve irfan müesseselerinin geliştirilmesi daha da önemlidir. Akademi bundan sonra yarının işi olacaktır. " görüşündedir.

Söz konusu görüşler akademinin ya gereksiz olduğunu ya da kurulmasının daha sonraya bırakılmasını ifade etmektedir. Yabancı diye kaldırılıp yerine "öz Türkçe” olarak konulan ama birçoğu uydurma olan kelimelerle ilgili herhangi bir değerlendirme yapılmamaktadır. Sadece eski-yeni mantığıyla yapılan söz konusu değişimin ilmi açıdan değerlendirilmesinin nasıl bir mahsuru olacağ1 itirazı düşündürücüdür. Ayrıca birçok kişinin veya kurumun Türkçede açtı̆̆ı yara sürekli derinleşmekte iken Türkçedeki değişimi ilmi bir tabanda kontrol edecek bir mekanizma, neden geciktirilmek istenmektedir.

M. Cevdet Bey: "En küçük hükümetlerde bile akademi bulunduğu halde Türkiye'nin bundan mahrumiyeti pek elimdir. Akademi olmadan dil perişanlı̆̆ ifade edilemez." demektedir. 
H. Cahid Yalçın: "Madem ki fakültemiz, darülfünunumuz, müderrislerimiz, mütehassıslarımı, âlimlerimiz var. Bunlar oluyor da akademi niçin olmasın? Zannederim ki, mevcut irfan müesseslerimize ilave edilecek bir akademi, hey'et mecmua ile mütenasip olmaktan geri kalmayacaktır."

Hasan Ali Bey ve Zeki Mesud Bey: "Avrupa'daki manaslyla akademi, ilim dünyamızın ileride gerçekleştireceği bir ideal olmall ve ona doğru yürümeliyiz. Bunda ne gibi bir beis vardır?"

Galip Ata Bey: "Bizde de akademi bulunmasinı istememek memleketimizde ulumun terakkisi, Türkiye'nin daha ziyade güzelleşmesi ve Türk dilinin daha mükemmel ve daha zarif olması lüzumunu inkâr etmektir."

Şeklinde yorumlar yapılmaktadır. Akademi kurulmasında olumlu görüş bildirenlerin sayısı bir hayli fazladır. Dilimizi kontrol edebilecek, değişimlere ayak uydurabilecek ve milli kültümüz çerçevesinde dil meselesini en ince ayrıntısına kadar inceleyecek bir kurumun varlığı şüphesiz gereklidir. Dönemin siyasi, ekonomik ve sosyal şartlarının ortaya çıkardığı değişimlere ayak uydurmak yani kültürümüzün taşıyıcısı ve kimliğimizin önemli bir parçası olan dilimizi her türlü gereksiz müdahaleden kurtarmak bir dil akademisinin varlığı ile mümkün gözükmektedir.

Akademi ile ilgili olumlu ve olumsuz görüşleri M. Fuad Köprülü toparlayarak şu cümlelerle değerlendirmiştir:

"Bizim memleketimiz için Fransız akademisi tarzında yani, sade yetişmiş sanatkârlar sinesinde toplayacak bir müesseseden ziyade, en genç memleketlerin bile tatbikine uğraştıkları (Ulum Akademisi) tarzında bir teşekkülün daha müfit olacağı kanaatindeyim. Küçük, mütevazı bir akademik merkezle onun etrafinda müstakbel âlimleri yetiştirmekle mükellef enstitüler, müzeler ve encümenlerden terekküp edecek bir müessese, bugün için parlak görülmese bile, istikbal için pek müfid olabilir. Böyle bir ilmi merkez, eldeki kuvvetlerden de azami nisbette istifade edebilmek çarelerini kolaylıkla bulur." (Tevetoğlu 1968:24).

Yakup Kadri Karaosmanoğlu, Atatürk'ün akademi konusunda anketi dikkatlice takip edip inceledikten sonra: “ -Henüz üniversitemiz Avrupa üniversiteleri ayarında tam olarak gelişmemiş iken akademi kurmak erkendir. İlim ve sanat üzerinde otorite olacak böyle bir müessese bir kere cahilkifayetsiz kişilerin ellerine kalırsa Türk ilim-fennine ve edebiyatına tamiri mümkün olmayan zararlar verebiliriz" diyerek, bu meseleyi daha ileriki yıllara ertelediğini aktarmaktadır (Tevetoğlu 1968: 25). Buna karşılık Tevetoğlu (1968: 26) Afet İnan'ın hatıralarında yer alan şu ifadeyi de aktarmıştır: “Atatürk, Türk Tarih ve Dil Kurumları'nın geleceğini akademi olarak görmektedir." Geleceği akademi olarak görülen Türk Dili Tetkik Cemiyetine de zaman zaman birçok eleştiri getirilmiştir.

1960'lı yıllarda, dönemin siyasi koşulları incelendiğinde; ticaret, sağlık, ekonomi gibi daha birçok alandaki gelişmeleri planlamak ya da yönetmek için o dönem üniversitelerinde ders veren ilim adamlarına yer veren politikacılar dil meselesi ile fazlaca alakadar olmamışlardır. Bu durum ise keyfi uygulamaları beraberinde getirmiştir. Akademi tartışmaları çok eskilere dayanmaktadır. İlk zamanlarda "Akademi" nin kurulması dil meselesindeki birçok sorunu başlamadan bitirecek, tartışılan çoğu konuyu da ilmi bir zemine taşıyabilecekti. Siyasi kaygıların dışında tutulamayan Türkçe, günümüzde sadeleşme sorunu yaşamasa da geçmişte aldığı birçok yaranın acısını; günümüzde genç neslin kökleriyle, kültürüyle bağını zedeleme ya da yer yer koparma noktasına getirmiştir. Bu acının yok olması ve milli şuurun ayakta durmasının temeli de Akademi ile sağlanabilirdi.

\section{Akademi ve Türk Dil Kurumu}

Değişen ve gelişen Türkiye'de, çağın gerektirdiği birçok değişikliği ilmi bir zemine oturtabilecek akademiler özellikle 1968-1969 yıllarında oldukça fazla tartışılmıştır. Kültürün ve 
kimliğin temeli olan "dil"in değişim ve gelişiminin ilmi çerçevede ele alınıp değerlendirildiği bir kurumun kurulmasına özellikle "Türk Dil Kurumu” oldukça karşı çıkmıştır. Türk Kültürü dergisinde çeşitli yayınlar vasıtasıyla TDK bu konuda sert bir biçimde eleştirilmiştir. İlhan Çeneli (1969) TDK'nın akademi kurulmasına yönelik "tutucu-devrimci" değerlendirmesine şu şekilde karşı çıkmıştır:

“Türkiye’ de akademiye büyük ihtiyaç vardır. Bu akademi dildeki başıboşluğa son verecek, dilimizi ilim ve felsefe yapabilecek bir duruma getirecektir. Bugünkü TDK mensuplarının "akademiler tutucu olur, biz devrimciyiz" demeleri de doğru değildir. Bu akademi ilk önce dilimizi yetkisiz kişilerin müdahalesinden kurtaracaktır. Ama her bir kaide değiştiren TDK bunu yapamaz yapamamaktadır. Yazı dilimize girmiş 7000 batı kaynakl kelimeye karşılık bulacağ yerde "hazine" yi kaldırıp yerine "gömü”yü koymaya çalışan TDK'dan dil meselemizi halletmesi de beklenemez" (Çeneli 1969: 44).

O dönemki şartları dikkate alındığında dil konusunda otorite olan birçok aydının yazdıkları ve eleştirileri, TDK tarafından dikkate alınmamıştır. Dönemin TDK çalışanları, uydurmacı dil çerçevesinde hareket ettiklerinden ilmi bir bakış açısı ile olayları değerlendirmeleri mümkün olmamıştır. Aksi halde millî, alanında otorite kişileri ve sistemli bir biçimde Türk medeniyetini geliştirmeye çalışan tüm unsurları bünyesinde barındırabilecek bir kuruma karşı çıkmak ilim ile izah edilemez. N. Hacıeminoğlu (1968) uydurmacılığın sorumlusu olarak gösterdiği TDK'yı şu şekilde eleştirmiştir:

“Türk Dili Tetkik Cemiyeti kurulduğu günden beri geriye gitmektedir. Dilimizi bozan ve anarşiye götüren uydurmacılığı ön plana çıkarmıştır. Üstelik bu sakat ve tehlikeli hareketi kendi sınırları içinde yapmakla yetinmeyip, politik baskı ve şantajlarla Milli Eğitim Bakanlı̆̆ı'na, TRT'ye ve diğer devlet dairelerine de bulaştırmıştır. Uydurmacılığın sorumlusu bu kurumdur. Sade Türkçenin zirvesi sayllan Reşat Nuri ve Sait Faik gibi yazarların eserlerini bile "özleştirmeye” kalkışan bu kurumdur. Sonunda Atatürk'ün "Nutuk" unu uydurma dile çevirip gülünç duruma düşüren yine bu kurumdur. Dil bilginlerine gerici, devrim düşmanı deyip milletin bütün huzursuzluğuna göz yuman da yine bu kurumdur (Hac1eminoğlu 1968: 37).

Bu keyfiliğin son bulması ancak dil konusundaki yetkili kişilerden oluşan bir akademi ile mümkün gözükmektedir. Ayrıca dil konusunda yürütülen değişim sürecinde dil âlimlerinde başvurulmadığı gibi dil meselesindeki eserlerin hiçbirinin de dikkate alınmadığı aşikârdır. Aksi halde bu uydurmacılık politikasının yürütülmesinin mümkün olamayacağı düşünülmektedir. Yazılı ve görsel basının, dili her gün biraz daha bozduğunu ve bu gidişe artık dur demek zamanın geldiğini ifade eden Timurtaş (1968: 53) akademinin; kelimelerle ilgili her türlü tasarrufu elinde bulunduran, dile ait kaidelerini belirleyen bir kurum şeklinde olması gerektiğini ifade ettikten sonra TDK' ya şu eleştirilerde bulunmuştur:

1851'de Encümen-i Dâniş devam edebilseydi çoktan bir ilimler akademisine sahip olacaktık. Atatürk, Dil Kurumunu kurarken ileride oluşacak akademinin tohumlarını atmıştır. Oysa kurum ilimden uzak bir hava içerisinde Türk dilini tahriple meşguldür. Dil akademisinin özleştirme akımına karşı kurulacă̆ı tezviratını yaymaya çalışlyorlar. Bunlar hala bilmiyorlar ve anlamiyorlar ki, bütün milletin şikâyeti özleştirmeden değil, uydurmacılıktandır, kendileri uydurmacılık bataklı̆̆ına saplanmışlardır (Timurtaş 1968: 54).

Bilgisiz ve kötü niyetli insanlardan uzak, milli, zengin ve istikrarlı bir Türk diline neden engel olunduğu düşündürücüdür. Nesiller arasındaki bağlantıyı koparmaya çalışan "özleştirmeci" yaklaşımların Türk dilinin gelişmesine engel olduğu gibi, Türk birlik - beraberliğini de yok etmeye çalıştı̆̆ 1 ifade edilebilir. TDK' ya diğer bir eleştiri ise: 
“Türk Bilimler Akademisi'nin kurulmasiyla en büyük kazancımı, uydurma dilden, bizi birbirimize düşürmekten başka faaliyeti bulunmayan bugünkü "Türk Dil Kurumu”"nun yanlış tutumundan, hatalı gidişinden kurtulmamıza yardımcı olacağına dair inancımızdır. Atatürk'ün kurduğu bir tesis olduğu halde, onun ideallerine ve işaretlerine aykırı şekilde birleştirici değil bölücü bir davranışla; dilimizi bozmak ve ana ile evladı birbirini anlamayacak hale getirmek için aşırı çaba sarf ediyor. Bunun karşıllğında ne yapsak ne yazsak fayda vermiyor inatla israrla yürüyorlar" (Erer 1968: 61).

cümleleri ile yapılmıştır. Toplumun bağını ortadan kaldırmaya çalışanlar, ananın evladını evladın da anasını anlayamadığı uydurma bir dil geliştirmeye çalışarak, kültürümüzün en temel taşıyıcısı olan aile kurumuna da büyük zararlar verilmiştir. Türk fikir ve ideal birliğini sağlamak ya da bu birliği daha ileri noktaya taşıyarak dünyadaki tüm Türkleri aynı ideal etrafinda buluşturabilecek olan "Türk Bilimler Akademisi”ne karşı çıkmanın izahı da mümkün gözükmemektedir.

Ömer Seyfettin (1918, Akt. Erer 1968: 61) ayrı Türk devletlerinin olabileceğini ama ayrı Türk milletlerinin olamayacağını ifade ederken "lisanda birleşmeye" vurgu yapmıştır. Ayrı lisanın, medeniyet coğrafyasında ilerlemeye çalışan Türkleri kuvvetlendiremeyeceğini ifade eder. Uydurmacı zihniyetin bu davranış ve tutumlarla yapmaya çalıştığı şeyi anlamak da mümkün görünmemektedir.

\section{Sonuç}

Tarihi seyre bakıldığında dilin sadeleşmesi zaman zaman alevlenip sonra da küllenen bir mesele olmasına rağmen tarafları memnun eden somut bir sonuca da ulaşamamıştır. Türk Kültürü Dergisinde incelen yazılar çerçevesinde bu tarihi seyir görülebilmektedir. Dergideki birçok aydın, dilin bu şekildeki bir sadeleşme anlayışıyla bir yere varamayacağını, söz konusu değişimin ise toplum açısından sorun oluşturacağını ifade etmektedir.

Öte yandan, öne sürülen kelimelere ve değerlendirmelere bakıldığında "özleştirme" yanlılarının aslında Türk dilinin şekillendiği kültürü yok etmeye çalıştıkları söylenebilir. Toplumun sosyal hayatında, milli ve İslami şuurunda açılmaya çalışılan bu gedik "dili yabancı dil boyunduruğundan kurtarma" sloganıyla süslenip sunulmaktadır. Dünyada birçok dilde o dilden olmayan çokça kelime vardır. Bu dillerin yabancı dillerin boyunduruğundan kurtulma gibi bir meselesi olmuş mudur? İnançlarını, milli hislerini, geçmişlerini kısacası ne olduklarını yansıtan dillerini yabancı dillerin tahakkümünde mi bırakmışlardır. Yapılmak istenilen "özleştirme" sırasında, uydurulan kelimelere ve bunların karşındaki görüşlerle ilgili yapılan değerlendirmelere bakıldığında; söz konusu değişimin kural tanımadan, daha çok ideolojik bir yaklaşımla yapıldığ 1 sonucunu ortaya çıkarmaktadır.

Bütün bu değişimin sonuçları günümüzde çeşitli şekillerde görülebilmektedir. 2014 y1lında Osmanlı Türkçesi ile ilgili çıkan çeşitli tartışmalar uydurmacıların toplumumuzu getirdiği noktayı ifade etmek bakımından çok önemlidir. Aslında bu tartışmalar 1960'lı yıllarda yapılmaya çalışılan kültürel yozlaşmanın tesirini de ifade etmektedir. Türk milli kültürüne ve Türk tarihine düşman olduğu düşünülen söz konusu kişiler; yıllar geçse de değişmeyen bir amaçla karşımızda durmaktadırlar; sınırlı bir kelime varlı̆ğna sahip bir Türkçe ve kültüründen kopmuş bir genç nesil. Murat Bardakçı 2014 yılının aralık ayında Osmanlı Türkçesi konulu yazısında bu uydurmacı zihniyetin varlığına şu cümlelerle dikkat çekmektedir:

Eski Türkçe öğretiminin getireceği asıl fayda, mezar taşlarını okuyup asırlar öncesinin ağdal resmî metinlerini anlayabilmek gibisinden hayaller değil; bugün yüz, haydi bilemediniz yüzelli-ikiyüz kelimeye sıkışmış ve fukaranın da fukarası hâline getirilmiş olan Türkçe'nin kelime dağarcığının yeniden zenginleşmesi olacaktır. Genç neslin doğru dürüst konuşup meramını ifade edebilmesinin yolu Türkçe'nin en azından 20. asırdaki üstadlarını, meselâ Refik Halid'i, Hüseyin Rahmi'yi ve diğerlerini asıllarından okuyabilmelerinden, hattâ çok sonraların, 1950’lerin gazetelerini 
anlayabilmelerinden geçer. Tozu dumana katarak devam eden Osmanlı Türkçesi tartı̧̧malarına geçen gün "Dil Derneği " de müdahil oldu ve "orun", "siyasa", "tümce”, "savaşım", vesaire gibi takır-tukur "sözcüklerle" dolu bir açıklama yayınladl...

“ - Derneğin yönetim kurulu başkanı olan ve açıklamanın altında imzası bulunan hanimefendiye hatırlatayım:

Dil konusunda güya akademik açılama yapma iddiası ile kaleme sarllıp ortaya siyasî bir metin koyduğunuz takdirde bile, vereceğiniz örnekleri internetten kesip yapıştırmak yerine kitap karıştırarak bulmak zorundasınız hanımefendi!

Böyle yapsa idiniz, yani Âşık Paşa'nın "Türk diline kimseler bakmaz idi" şeklindeki en meşhur misrâın bile internet yerine zahmet buyurup Garipnâme'den almış olsaydınız öyle eğip bükmez, veznini bozup tuhaf hâle getirmez, yani tek bir satırı bile yanlıs yayınlama gibisinden bir ayıp etmezdiniz.

Sizin "orunsal savaşım”"ınıza kurban olsunlar!

Osmanlı Türkçesini; Arapçaya, geri kalmışlığa ya da İslamcılığa indirgeyip yok etmeye çalışan zihniyet, genç neslin atalarından bihaber yetiştirilmesine çalışmaktadır. Üzerinde yaşanılan toprak parçasını "vatan" yapan melekelerin genç nesillerin zihinlerinden silinmeye çalışılması en az dokuz asırlık geçmişe sahip maziyle köprü olan Türk dilini zihinlerden silmek demektir. Dede Korkut hikâyelerinden, Ahmet Yesevi'nin hikmetlerine, Kerem ile Aslı'dan Yahya Kemal'in şiirlerine ve daha nicelerinden bihaber bir neslin; milli kültür şuurundan ve Türk dilinin zenginliğinden uzak yetişeceği açıktır.

Tanzimat ile başlayıp çeşitli merhalelerden geçen Türk dilinin sadeleşme/özleşme meselesi incelediğimiz dönemde ve sonrasında da zaman zaman gündeme gelmeye devam etmiştir. Ömer Seyfettin ve Ziya Gökalp gibi milli edebiyatçılar, Osmanlı yazı dilinin lüzumsuz yabancı kelimler ve gramer şekilleri ihtiva etmesinden duydukları rahatsızlıkları ifade etmişlerdir. Aydınların kalem aldığı suni Osmanlı Türkçesi ile halkın konuştuğu dil arasındaki derin uçurum gittikçe büyümesi sadeleşme meselesinin; bu boyutuyla diğer aydınlar tarafından da aynı şekilde değerlendirilmesini ortaya çıkarmıştır. Meseleye milli bir dava olarak bakan dönemin aydınlarının çabalarıyla birlikte hiçbir resmi-siyasi zorlama olmadan yazı dili tabiî gelişme çizgisi doğrultusundaki yatağına kavuşmuştur (Hacieminoğlu, 2011: 8). Görüldüğü gibi mesele "özleşme" değildir. Bu mesele y1llar önce çözüme kavuşturulmuştur. 1960'lı yıllarda bu işin tekrar alevlendirilmesi Türk kültürünü yok ederek Türkçeyi ifade gücü yetersiz bir dil haline getirmek isteğinden başka ne ile açıklanabilir. Dönemin siyasi şartları sonucunda devlet kurumlarına yerleşen ve Osmanlı Türkçesini bir medeniyet dili olarak görmeyenler, aslında dilimize ve kültürümüze, onların gelişmesine zarar vermişlerdir.

Bugün dilimizde, tarihi seyir içerisinde oluşmuş sayılmayacak kadar çok kelime bulunmaktadır. Bunları atmaya çalışmanın kültürü yok etmekle bir olduğunu ifade eden Timurtaş, (Bozgeyik, 1981: 14) sadece Türkçeleşememiş kelimelerin dilden atılması gerektiğini ifade ederek aslında tutulması gereken yola da dikkat çekmiştir. Kültürüne yabancı dedesi ile irtibat kuramayan nesillerin Türk milletine hizmet etmesi beklenemeyeceği gibi özünden kopuk bir neslin hizmetinin de sınırlı kalacağı düşünülmektedir. Öze bağlı olmayı Nihal Bengisu Karaca (2014) Osmanlı Türkçesi tartışmaları çerçevesinde şöyle ifade etmektedir:

"Ille de istemezük" diyorsanı, o zaman "Neden bizde bir 'Downton Abbey' çekilemiyor?" diye hüzünlenmeyeceksiniz. İngilizler çocuklarına hâlâ eski İngilizce ögrettikleri içindir ki, bugün hâlâ "Ingiliz" diye bir şey var. "Viktoryen üslup" var, "English country style" var, "centilmen" var, "Robin Hood ve Şen Adamlarl" var, "snobluk" var, "Devonshire'ın kremalı çayl" var, "serinkanlılık" tescilli Ingiliz hasleti; "bahçe işleri ile uğraşmak", "5 çayl", bir medeniyet sembolü olarak yaratıc 
"ikiyüzlülük”, hepsi adeta İngiliz patentli. Çocukların fantezi dünyası dün "Alice Harikalar Diyarında” ile şekilleniyordu, bugün Hogwarts ve Harry Potter ile. Çünkü bir milletin kendine ilişkin algısl, gündelik hayatı taşıyan sosyolojiyi, kültürü ve hatta popüler kültürü canls tutar.

Dil akademisine karşı çıkan, uydurma kelimelerle kültürümüzü baltalamaya çalışan üstelik de bunu o dönemin TRT ve TDK gibi devlet kurumlarıyla yapan zihniyet, tarihi büyüklügü̈müzü fetih ve cenk hikâyelerinden ibaret saymaktadır. Bugün tarihini film-dizilerden öğrenen, ne dediği anlaşılmayan, söz varlığı yetersiz Osmanlı düşmanı nesil şüphesiz bu uydurmacı zihniyetin yaptıklarının sonucudur. Geçmişini beğenmeyen Osmanlı'ya laf söylemeyi marifet sayanların Osmanlı Türkçesine makul bakmaları da beklenemez. Oysa kadim geleneklerin oluşmasının kültürle mümkün olduğu kültürün yegâne taşıyıcısının da dil olduğu açıktır.

Dile istedikleri gibi yön vermeye çalışan "özleştirme" yanlıları akademiye de karşı çıkmışlardır. Söz konusu zihniyet akademinin dil konusunda yapacağı ilmi çalışmaların etkisini bildiğinden olsa gerek dil akademisine karşı çıkmıştır. Hatta TDK'dan akademiyle alakalı açıklama yapan veya makale kaleme alan birçok ilim adamı "devrime karşı" diye yaftalanıp kurumdan uzaklaştırılmıştır.

Sonuçta olması gereken, keyfe göre ve ideolojik bir mantıkla değil, ilmin gereklerine göre hareket etmektir. Sosyal hayatın ve zamanın çeşitli değişiklikler getirdiği/getireceği muhakkaktır. Söz konusu değişiklikler milli kültür temelinde dile yansıtılmalıdır. Tüm siyasi ve ideolojik maksatlardan bağımsız bir biçimde ele alınması gereken dil meselesi herkesin söz söyleyeceği bir alan olarak basitsıradan algılatılmamalıdır. Hedef; aşırıya kaçmadan, dilin tabi seyrini etkilemeden, kültürümüze zarar vermeden değişiklik- yenilik yapmak ve Türkçeyi geliştirerek sonraki nesillere ifade gücü yüksek zengin bir dil bırakmak, olmalıdır.

\section{KAYNAKÇA}

Akarsu, B. (1998). Dil- Kültür Bağlantısı. İstanbul: İnk1lâp Kitabevi.

Aksan, D. (2003). Her Yönüyle Dil Ana Çizgileriyle Dil Bilim. Ankara: Türk Dil Kurumu Yayınları.

Aktaş, Ş \& Gündüz, O. (2011). Yazılı ve Sözlü Anlatım. Ankara: Akçağ Yayınları.

Balaban, A. (2015). Yabancı Kelimelere Karşı1lı Bulmada Karşılaşılan Sorunlar ve Çözüm Önerileri. Turkish Studies- International Periodical For The Languages, Literature And History Of Turkish Or Turkic, (10)8, 573-596.

Bozgeyik, B. (1981). Dil Davası (Faruk Kadri Timurtaş İle Mülakat). İstanbul: Yeni Asya Yayınları.

Çeneli, İ. (1969). Dilimiz Üzerine Düşünceler. Türk Kültürü Dergisi, (84), 39-45.

De Rosay, C. (2006), Ahmet Mithat Efendi'nin Eserlerinde Batılılaşma. (Yayınlanmamış yüksek lisans tezi). Yıldız Teknik Üniversitesi/ Sosyal Bilimler Enstitüsü: İstanbul.

Erciyas, O. (2010). Özleştirme Çalışmaları Işığında Türk Dil Kurumu Özleştirme Kılavuzu. Turkish Studies- International Periodical For The Languages, Literature And History Of Turkish Or Turkic, (5)3, 1188-1197.

Erer, T. (1968). Türk Bilimler Akademisi. Türk Kültürü Dergisi, (67), 60-67.

Ercilasun, A. B. (1980), Türk Dili Üzerine, “Türk Dili” Sempozyumu 26-27 Aralık 1980. İstanbul: Kervan Kitapçıllk: 33-62.

Ergin, M. (1969). TRT' nin Dili, Türk Kültürü Dergisi, (78), 1-8. 
..(2002). Türk Dil Bilgisi, İstanbul: Bayrak Yayınları.

Felek, B. (1969). Bazı Yeni Kelimeler Üzerine Düşünceler, Türk Kültürü Dergisi, (76), 13-15.

Güneş, F. (2013). Türkçe Öğretimi Yaklaşımlar ve Modeller. Ankara: Pegem Akademi.

Özcan Gönülal, Y . (2011). Dil-Toplum İlişkisi Açısından Türkiye'de 1940 Sonrası Dil Tartışmaları Üzerine Bir Değerlendirme. Turkish Studies- International Periodical For The Languages, Literature And History Of Turkish Or Turkic, (6)1, 1127-1137.

..(2012), Cumhuriyet Dönemi Dil Tartışmalarının Türk Dili Eğitimine Yansımaları

Toplum Dil Bilimi Bakımından Bir İnceleme. (Yayımlanmamış doktora tezi). Dokuz Eylül Üniversitesi, İzmir.

Hacıeminoğlu, N. (2011). Türkçenin Karanlık Günleri. (6. baskı). İstanbul: Türk Edebiyatı Vakfı Yayınları.

İnan, A. (1968). Bazı Yeni Kelimeler Üzerine Düşünceler, Türk Kültürü Dergisi, (71), 1-6.

Köymen, M. (1968). Milletler ve Akademiler. Türk Kültürü Dergisi, (67), 2-10.

Levend, A. S. (2010). Türkçe'nin Gelişme ve Sadeleşme Evreleri. Ankara: Dil Derneği.

Öksüz, Y. Z. (2004). Türkçe'nin Sadeleşme Tarihi Genç Kalemler ve Yeni Lisan Hareketi, Ankara: Türk Dil Kurumu Yayınları.

Özdemir, M \& Süğümlü Ü. (2013). Dilde Sadeleşme ve Dil Akademisi Tartışmaları: Türk Dili Dergisi (1976). Turkish Studies-International Periodical For The Languages, Literature And History Of Turkish Or Turkic, (8)9, 2269-2295.

Özdemir, M \& Dağtaş A. (2014). Dilde Sadeleşme Tartışmaları: 1970 Yılı “Türk Dili” Dergisinde Arapça, Farsça ve Batı Dillerinden Gelen Kelimelere Karşı Takınılan Tavır. Mustafa Kemal Üniversitesi Sosyal Bilimler Enstitüsü Dergisi, (11)26, 27-51.

Özdemir, M \& Yegen, Ü. (2016). Ahmet Mithat Efendi'nin "Karnaval”, "Henüz 17 Yaşında” ve "Vah" Romanlarında Batı Medeniyeti Eleştirisi. Uluslararası Türkçe Edebiyat Kültür Eğitim Dergisi, 5(1), 324-350.

Özyurt, C. (2005). Dilde ve Edebiyatta Uluslaşma: Genç Kalemler ve Yeni Lisan Hareketi. Muhafazakâr Düşünce, (5), 53-78.

Taş, K. (2002). Tanzimat ve Batılılaşma Hareketlerine Sosyolojik Bir Yaklaşım. İlahiyat Fakültesi Dergisi, (7), 87-94

Temir, A. (1968). Bilimler Akademisi Kurulması İle İlgili Çalışmaların Son Durumu. Türk Kültürü Dergisi, (67), 62-67.

Tevetoğlu, F. (1968). Türk Akademisi ve Atatürk. Türk Kültürü Dergisi, (67), 14-32.

Timurtaş, F. K. (1968). Türk Akademisi Kurulurken. Türk Kültürü Dergisi, (67), 52-55.

Türk Dil Kurumu (2010). Türkçe Sözlük. Ankara: TDK Yayınları.

Uludağ, E. (2009). Dilde Sadeleşme ve Türkî-i Basît Hakkında Düşünceler. Turkish StudiesInternational Periodical For The Languages, Literature And History Of Turkish Or Turkic, (4)5, 293-329.

Yetişgin, M. (2005). On Dokuzuncu Asırda Avrupalının Gözüyle Türk İmajı. KSÜ Sosyal Bilimler Dergisi, (1), 70-79. 